\title{
Negative transcriptional regulation of the mce3 operon in Mycobacterium tuberculosis
}

\author{
María P. Santangelo, ${ }^{1}$ Jorge Goldstein, ${ }^{1}$ Alicia Alito, ${ }^{2}$ Andrea Gioffré, ${ }^{1}$ \\ Karina Caimi, ${ }^{1}$ Osvaldo Zabal, ${ }^{3}$ Martín Zumárraga, ${ }^{1}$ Maria I. Romano, ${ }^{1}$ \\ Angel A. Cataldi ${ }^{1}$ and Fabiana Bigi ${ }^{1}$
}

Author for correspondence: Angel A. Cataldi. Tel: +54114621 1447 or 0199. Fax: +54 1144812975. e-mail: acataldi@correo.inta.gov.ar

Institute of Biotechnology', Institute of Pathobiology2, Institute of Virology3, CICVyA/INTA, 1712 Castelar, Argentina

\begin{abstract}
mce3 is one of the four mce operons in Mycobacterium tuberculosis that encode exported proteins with a probable role in the virulence of this bacterium. Upstream of mce 3 there is a putative regulatory gene (Rv1963) that harbours a double tetR-family signature. To study the role of this putative regulatory gene in the transcriptional regulation of the mce 3 operon, Mycobacterium smegmatis mc $^{2} 155$ and $M$. tuberculosis H37Rv strains that harboured gene fusions between the mce 3 promoter region and the Escherichia coli lacz gene, either containing or not containing the Rv1963 gene, were used. The presence of the Rv1963 gene in the strains greatly reduced $\beta$-galactosidase activity, suggesting that the Rv1963-encoded protein is a transcriptional repressor of the mce3 operon. Expression of mce 3 by recombinant $M$. tuberculosis was increased when it was grown in a macrophage-like cell line (J774), compared to the level of expression seen when the recombinant bacterium was grown under in vitro conditions. However, no lifting of repression was induced. The mce 3 promoter was defined by deletion and cloning of the Rv1963-Rv1964 intergenic region in a $200 \mathrm{bp}$ DNA fragment harbouring the region upstream of the Rv1964 start codon. Gel-shift experiments determined that the Rv1963-binding site was located in this region. These results indicate that the mce 3 operon is transcriptionally regulated and that under certain, unknown, conditions repression of gene expression could be lifted.
\end{abstract}

Keywords: repressor, tetR, reporter

\section{INTRODUCTION}

Tuberculosis (TB), a chronic illness caused by Mycobacterium tuberculosis, is still a major disease worldwide. According to the World Health Organization, TB is a considerable public health problem in Latin America, Asia and Africa. During the last few years, an increase in the incidence of TB has been observed and this has been attributed to weak control programmes, the AIDS pandemic, which predisposes individuals to developing TB, and the appearance of M. tuberculosis strains that are resistant to first-line antibiotics (Murray et al., 1990).

Unfortunately, many aspects of the infection and disease

Abbreviations: mce3R, Rv1963; TSP, transcription start point; BAC, bacterial artificial chromosome. process of tuberculosis at the cellular and molecular level still remain unknown. According to Smith (1984), to infect and cause disease pathogenic mycobacteria must be able to (i) colonize the host's lung tissues, (ii) enter the host's cells, (iii) multiply in the environment of the host's tissues, (iv) resist or interfere with the host's defence mechanisms and (v) cause damage to the host's tissues. Despite the formidable advances in molecular biology in recent years, the identification of the virulence factors of pathogenic mycobacteria (i.e. M. tuberculosis, Mycobacterium bovis and Mycobacterium leprae) has been delayed, when compared to the identification of the virulence factors of other infectious bacteria. Factors contributing to this situation include the lack of a phenotype clearly associated with virulence in pathogenic mycobacteria and the scarcity of genetic tools for transforming and mutating M. tuberculosis. Steps to solving the latter problem have been taken, as improved 
genetic tools have allowed the identification of virulencerelated genes in M. tuberculosis (Camacho et al., 1999; Cox et al., 1999). The most-employed virulenceassociated attribute of M. tuberculosis is its persistence in the infected organism or in cultured cells (Bange et al., 1999).

We have previously identified a $12.7 \mathrm{~kb}$ region in the genome of $M$. tuberculosis that is absent from the genome of M. bovis (Fisanotti et al., 1997; Zumarraga et al., 1999). This $12.7 \mathrm{~kb}$ fragment was present in all of the M. tuberculosis strains tested and was absent from all of the M. bovis, Mycobacterium microti and Mycobacterium africanum strains tested. The region is located near the 3' end of the RD2 element described by Mahairas et al. (1996), a $14 \mathrm{~kb}$ genomic locus present in M. bovis but absent from some strains of $M$. bovis BCG, suggesting that this region suffers from genetic instability. Sequence analysis of ORFs within the $12.7 \mathrm{~kb}$ fragment of the M. tuberculosis genome demonstrated that it mostly encodes exported proteins. One of the ORFs is highly homologous to the invasin-like protein described by Riley and colleagues (Arruda et al., 1993; Chitale et al., 2001). This region was also described by Gordon et al. (1999) as RD7. The presence of genes encoding an invasin-like protein and many membrane or secreted proteins within the $12.7 \mathrm{~kb}$ region suggests that this region may play an essential role in the host-pathogen interaction of $M$. tuberculosis. The ORFs within the region are organized as a putative operon, which is similar in its sequence and organization to three other M. tuberculosis regions (operons mce1, mce 2 and mce4) described by Cole et al. (1998). The lack of similarity of the genes encoded by this putative operon to genes from other bacterial species suggests that they may play a specific role in the physiology or virulence of $M$. tuberculosis. Flesselles et al. (1999) reported that a BCG strain mutated in mce 2 exhibits a reduced ability to invade the non-phagocytic epithelial cell line HeLa, which supports the idea of a role for mce operons in virulence. Harboe et al. (1999) demonstrated production of the mce1-encoded proteins using cell extracts from M. tuberculosis and M. bovis BCG. Mce1 proteins are recognized by the antibodies of TB patients (Ahmad et al., 1999), indicating in vivo expression of the mce 1 operon. At the genetic level, the four mce operons appear to have evolved from a common ancestor. The four operons may play different roles in the infection process, may be expressed at different times along growth phases or the infection process, or they may simply serve to protect essential virulence genes against mutations. In the present study, the regulation of the expression of the $m c e 3$ operon was investigated, to gain an insight into the role of this operon in M. tuberculosis. Our results show the presence of a repressor that controls mce 3 transcription.

\section{METHODS}

Bacterial strains and culture media. All cloning steps were performed in Escherichia coli DH5 $\alpha$. E. coli BL21( $2 \mathrm{DE} 3)$ was used for recombinant protein production. Regulation studies were performed in Mycobacterium smegmatis $\mathrm{mc}^{2} 155$ or in M. tuberculosis H37Rv. E. coli was grown in Luria-Bertani (LB) broth or on LB agar. Both mycobacterial species were grown in either Middlebrook $7 \mathrm{H} 9$ medium supplemented with $0.05 \%$ Tween 80 or Middlebrook 7 H11 medium supplemented with oleic acid/albumin/dextrose/catalase (OADC). When necessary, $20 \mu \mathrm{g}$ kanamycin $\mathrm{ml}^{-1}$ was added to the media. Electrocompetent Mycobacterium cells were prepared according to Parish \& Stoker (1998). Mycobacterial strains were transformed by electroporation using a Bio-Rad Gene Pulser, as described by Parish \& Stoker (1998). Following electroporation, $M$. smegmatis and $M$. tuberculosis were plated onto Middlebrook 7H11 medium supplemented with OADC and kanamycin.

DNA manipulations. Standard methods were used for restriction-endonuclease digestion of plasmids, for DNA ligations and for other manipulations. Isolation of plasmid DNA was performed using the Wizard Minipreps SV Kit, according to the manufacturer's instructions (Promega). DNA from M. tuberculosis was prepared according to van Soolingen et al. (1991).

Construction of lacZ reporter fusions. Details for the plasmids, vectors and primers used in this study can be found in Table 1. To create fusions with the E. coli lac Z gene, the regions containing the $R v 1963-R v 1964$ intergenic fragment including or not including the Rv1963 gene were amplified by PCR and cloned into the promoter-probe vector pJEM15 (Timm et al., 1994). The resulting plasmids were called p1963-P3 (plus $R v 1963$ ) and $\mathrm{pP} 3$ (minus Rv1963). All amplified fragments were cloned into either pGEM-T (Promega) or pPCRII-TOPO (Invitrogen), before being transferred to pJEM15. Fragments (100 and 206 bp in length) from upstream of the $R \nu 1964$ gene start codon were also fused to a promoterless lac $Z$ gene, resulting in plasmids pP3-100 and pP3-200, respectively (Table $1)$.

The template for PCR was a bacterial artificial chromosome (BAC) containing the mce3 operon, which was kindly provided by Dr S. T. Cole (Institut Pasteur, France). M. tuberculosis genomic DNA was used as a template for amplification of the mce 2 operon.

Different deletions of the $R v 1963-R v 1964$ intergenic region were obtained as follows. The pPCRII-TOPO intermediate constructs p1963-P3 and pP3 were separately digested with NheI and SalI; the digest products were then ligated. The inserts from the resulting plasmids were transferred to BamHIlinearized pJEM15 (see Table 1), resulting in p1963-P3 $\Delta$ Nhe and pP3 3 Nhe (for NheI deletions), and p1963-P3 $\Delta$ Sal and pP3 3 Sal (for SalI deletions). An XmaI-AgeI deletion was obtained by digestion of p1963-P3 with XmaI and AgeI. The digest products were ligated and introduced into linearized pJEM15, resulting in pP3 XXma/Age (Table 1).

Cloning and expression of $\boldsymbol{R} \boldsymbol{v} 1963$. $R v 1963$ was amplified from $M$. tuberculosis BAC DNA and cloned into pRSET-A (Table 1). The resulting plasmid, pRSET1963, was introduced into E. coli BL21( $\lambda \mathrm{DE} 3)$. E. coli BL21(pRSET1963) was then grown in LB broth at $28{ }^{\circ} \mathrm{C}$. Expression of the Rv1963 gene was induced by the addition of $0.1 \mathrm{mM}$ IPTG to the growth medium at the mid-exponential phase of growth. Soluble cell extracts from the culture were prepared by Fast Prep FP120 (Qbiogene) bead-beater disruption (40 s at $6.0 \mathrm{~m} \mathrm{~s}^{-1}$, using Lysing Matrix B). Proteins separated by SDS-PAGE (Cataldi et al., 1994) were assayed by Western blotting using antihistidine as the primary antibody (1:3000 dilution; Amersham Pharmacia) and alkaline-phosphatase-conjugated anti-mouseIgG as the secondary antibody (1:2000 dilution; Sigma). 
Table 1. Plasmids, vectors and primers used in this study

\begin{tabular}{|c|c|c|c|c|}
\hline Plasmid & \multicolumn{3}{|c|}{ Construction and characteristics } & Origin \\
\hline pJEM15 & \multirow{2}{*}{\multicolumn{3}{|c|}{$\begin{array}{l}\text { E. coli-mycobacterial promoter-probe shuttle vector for lacZ fusions; } \mathrm{Km}^{\mathrm{r}} \\
\text { PCR product from amplification with primers 1963P3up and P3rev was cloned into } \\
\text { pPCRII-TOPO and then moved to pJEM15; p1963-P3 carries the mce3 promoter } \\
\text { region and Rv1963 }\end{array}$}} & Timm et al. (1994) \\
\hline p1963-P3 & & & & This study \\
\hline pP3 & \multicolumn{3}{|c|}{$\begin{array}{l}\text { PCR product from amplification with primers P3up and P3rev was cloned into } \\
\text { pPCRII-TOPO and then moved to pJEM15; pP3 carries only the mce3 promoter } \\
\text { region }\end{array}$} & This study \\
\hline p1963-P3 $\Delta$ Sal & \multicolumn{3}{|c|}{$\begin{array}{l}\text { pPCRII-TOPO intermediate of p1963-P3 was digested with SalI, ligated and the } \\
\text { BamHI insert moved to pJEM15; p1963-P3 } 4 \text { Sal carries an SalI-SalI deletion in the } \\
\text { intergenic region and Rv1963 }\end{array}$} & This study \\
\hline $\mathrm{pP} 3 \Delta \mathrm{Sal}$ & \multicolumn{3}{|c|}{$\begin{array}{l}\text { pPCRII-TOPO intermediate of } \mathrm{pP} 3 \text { was digested with SalI, ligated and the BamHI } \\
\text { insert was moved to pJEM15; pP3 } \Delta \text { Sal carries an SalI-SalI deletion in the } \\
\text { intergenic region }\end{array}$} & This study \\
\hline p1963-P3 Nhe & \multicolumn{3}{|c|}{$\begin{array}{l}\text { pPCRII-TOPO intermediate of p1963-P3 was digested with NheI, ligated and the } \\
\text { BamHI insert was moved to pJEM15; p1963-P3 Nhe carries an NheI-NheI } \\
\text { deletion in the intergenic region and Rv1963 }\end{array}$} & This study \\
\hline $\mathrm{pP} 3 \Delta$ Nhe & \multicolumn{3}{|c|}{$\begin{array}{l}\text { pP3 was digested with NheI, ligated and the BamHI insert was moved to pJEM15; } \\
\text { pP3 } 3 \text { Nhe carries an NheI-NheI deletion in the intergenic region }\end{array}$} & This study \\
\hline $\mathrm{pP} 3 \Delta X m a / A g e$ & \multicolumn{3}{|c|}{$\begin{array}{l}\text { p1963-P3 was digested with XmaI and AgeI, ligated and the BamHI insert was } \\
\text { moved to pJEM15; pP3 } 3 \text { Xma/Age carries an XmaI-AgeI deletion, comprising the } \\
\text { intergenic region and } R v 1963\end{array}$} & This study \\
\hline pP3-200 & \multicolumn{3}{|c|}{$\begin{array}{l}\text { PCR product from amplification with primers P3200up and P3revk was cloned into } \\
\text { pGEM-T and then moved to pJEM15; pP3-200 carries a } 206 \text { bp fragment from } \\
\text { upstream of the Rv1964 start codon (ATG) }\end{array}$} & This study \\
\hline pP3-100 & \multicolumn{3}{|c|}{$\begin{array}{l}\text { PCR product from amplification with primers P3100up and P3revk was cloned into } \\
\text { pGEM-T and then moved to pJEM15; pP3-100 carries a } 100 \text { bp fragment from } \\
\text { upstream of the Rv1964 start codon (ATG) }\end{array}$} & This study \\
\hline pRSET1963 & \multicolumn{3}{|c|}{$\begin{array}{l}\text { PCR product from amplification with upregclo and lowregclo inserted into } \\
\text { pGEM-T and then moved to the PRSET-A expression vector }\end{array}$} & This study \\
\hline pRSET-A & \multicolumn{3}{|l|}{ Expression vector for histidine-tagged proteins; $\mathrm{Ap}^{\mathrm{r}}$} & Invitrogen \\
\hline pGEM-T & \multicolumn{3}{|l|}{$\mathrm{T} / \mathrm{A}$ cloning vector for PCR products; $\mathrm{Ap}^{\mathrm{r}}$} & Promega \\
\hline pPCRII-TOPO & \multicolumn{3}{|l|}{$\mathrm{T} / \mathrm{A}$ cloning vector for PCR products; $\mathrm{Ap}^{\mathrm{r}}, \mathrm{Km}^{\mathrm{r}}$} & Invitrogen \\
\hline Primer & Sequence & $\begin{array}{l}\text { Restriction } \\
\text { site }\end{array}$ & $\begin{array}{r}\text { Anne } \\
\text { temperat }\end{array}$ & $\begin{array}{l}\text { Amplicon size } \\
\quad(b p)\end{array}$ \\
\hline P3up & ggatccCGGCTCGAACCCCCTTCTTGCGCAC & BamHI & 66 & 896 \\
\hline P3rev & ggatccGGCGCGGCGCACCAGCTGGATTCGA & Bam HI & & \\
\hline 1963P3up & ggatccGGACACCTCATTCACACCGATAATG & BamHI & 58 & 2165 \\
\hline P3rev & ggatccGGCGCGGCGCACCAGCTGGATTCGA & BamHI & & \\
\hline P2up & ggtaccTGTTCTAACGATCTTCCGAA & $K p n \mathrm{I}$ & 48 & 139 \\
\hline P2low & ggatccTGCGCCCAGTGTGAATGAAG & BamHI & & \\
\hline P3100up & ggatccCGTACGCTCACCAATGTCACC & BamHI & 64 & 100 \\
\hline P3revk & ggtaccGGCGCGGCGCACCAGCTGGATTCGA & $K p n \mathrm{I}$ & & \\
\hline P3200up & ggatccTACTAGCAAGATACATCATAG & BamHI & 56 & 206 \\
\hline P3revk & ggtaccGGCGCGGCGCACCAGCTGGATTCGA & KpnI & & \\
\hline upregclo & ggatccATGGCATCCGTCGCCCAACCCG & BamHI & 61 & 1318 \\
\hline lowregclo & gaattcCTATGCGCGCAAGAGGTTACCT & EcoRI & & \\
\hline Low861 & GGATTCGATGCTGGGCCGTT & NA & 56 & na \\
\hline
\end{tabular}

NA, Not applicable, as used for primer-extension experiments.

PCR amplification. PCR amplifications were performed using Taq DNA polymerase (Promega) under standard conditions in a total volume of $50 \mu \mathrm{l}$. dNTPs were used at a concentration of $0.2 \mathrm{mM}$ each; $20 \mathrm{pmol}$ of each primer was used. The protocol used for amplification was as follows; denaturation at $94{ }^{\circ} \mathrm{C}$ for $3 \mathrm{~min}$, followed by 35 cycles of denaturation at 
$94{ }^{\circ} \mathrm{C}$ for $1 \mathrm{~min}, 1 \mathrm{~min}$ annealing at a temperature dependent on the primer pair used (Table 1) and elongation at $72{ }^{\circ} \mathrm{C}$ for $1 \mathrm{~min}$, with a final elongation at $72^{\circ} \mathrm{C}$ for $10 \mathrm{~min}$. A total of 2 ng of genomic M. tuberculosis DNA or BAC DNA was used as template.

RNA preparation. Total RNA from M. tuberculosis $\mathrm{H} 37 \mathrm{Rv}$ was isolated using the FastRNA Kit-Blue (Qbiogene). Briefly, $50 \mathrm{ml}$ of a culture was harvested during the exponential phase of growth by centrifugation at 3000 r.p.m. for $10 \mathrm{~min}$. The cell pellet was resuspended in $100 \mu \mathrm{l}$ diethyl pyrocarbonate (DEPC)-treated water and transferred to a $2 \mathrm{ml}$ screw-cap microcentrifuge tube containing $0 \cdot 1 \mathrm{~mm}$ diameter zirconium beads and FastRNA reagents (Qbiogene). Cells were disrupted by using a Fastprep FP120 bead-beater for $20 \mathrm{~s}$ at a speed of $6 \cdot 0 \mathrm{~m} \mathrm{~s}^{-1}$. Total RNA was then extracted from the cells following the manufacturer's instructions. After agarose-gel electrophoresis of the total RNA and staining of the gels with ethidium bromide, the different bands of rRNA were clearly visible, indicating that the RNA preparations were of a high integrity.

Primer extension. This was performed using the primer Low861 (Table 1). Ten picomoles of the non-phosphorylated primer were labelled by using $\mathrm{T} 4$ polynucleotide kinase (Promega) in the presence of $\left[\gamma^{32} \mathrm{P}\right] \mathrm{ATP}$. The specific activity of the primer was 8000 c.p.m. pmol ${ }^{-1}$. M. tuberculosis H37Rv RNA $(6 \mu \mathrm{g})$ and the labelled primer $(0 \cdot 1 \mathrm{pmol}, 33000$ c.p.m. $\mathrm{pmol}^{-1}$ ) were mixed in $7 \mu \mathrm{l}$ of $50 \mathrm{mM}$ Tris/ $\mathrm{HCl}(\mathrm{pH} \mathrm{8.3)}$ containing $0 \cdot 1 \mathrm{M} \mathrm{KCl}$. The reaction was then incubated at $94{ }^{\circ} \mathrm{C}$ for $1 \mathrm{~min}$, at $56^{\circ} \mathrm{C}$ for $10 \mathrm{~min}$ and then on ice for $15 \mathrm{~min}$. The mixture was adjusted to a final volume of $12 \mu \mathrm{l}$ by the addition of $1 \mu \mathrm{l}$ of a mixture containing the dNTPs ( $2.5 \mathrm{mM}$ each), $0.5 \mu \mathrm{l}$ of RNAsin (Promega), $2.2 \mu \mathrm{l}$ of $5 \times$ reverse transcriptase buffer $[0 \cdot 25 \mathrm{M}$ Tris $/ \mathrm{HCl}(\mathrm{pH} 8 \cdot 3), 0 \cdot 2 \mathrm{M}$ $\mathrm{KCl}, 36 \mathrm{mM}$ magnesium acetate, $0.01 \mathrm{M}$ DTT], $0.8 \mu \mathrm{l}$ of DEPC-treated water and $0.5 \mu \mathrm{l}$ avian myeloblastosis virus reverse transcriptase (Promega). Reverse transcription was performed at $42{ }^{\circ} \mathrm{C}$ for $45 \mathrm{~min}$; the reaction was stopped by the addition of $5 \mu$ l of stop buffer to the reaction mixture.

The reverse-transcription products were separated by PAGE $(6 \%$ acrylamide gel containing $8 \mathrm{M}$ urea), and were run alongside the sequencing products obtained with the Low861 primer. The gels were fixed by immersion in a mixture containing $5 \%(\mathrm{v} / \mathrm{v})$ methanol and $5 \%(\mathrm{v} / \mathrm{v})$ acetic acid. They were then exposed to X-ray film (Kodak X-Omat RS) for $24 \mathrm{~h}$ at $-70{ }^{\circ} \mathrm{C}$.

Computer analyses. Amino-acid-sequence alignments were generated by searching public databases using BLASTP (http:// www.ncbi.nlm.nih.gov/BLAST). M. smegmatis BLAST searches (http://www.tigr.org/tdb/mdb/mdbinprogress. html) were used to identify an Rv1963 orthologue in this bacterium. Domain analysis was performed by using PFAM (http://www.cgr.ki.se/Pfam). Prokaryotic promoter sequences were searched by using the prokaryotic option of the Neural Network Promoter Prediction algorithm of the Berkeley Drosophila Genome Project (http://www.fruitfly. org/seq_tools/promoter.html).

Measurements of $\boldsymbol{\beta}$-galactosidase activity. For in vitro determinations of $\beta$-galactosidase activity, $1 \mathrm{ml}$ of a recombinant $M$. smegmatis culture or $1 \mathrm{ml}$ of a recombinant $M$. tuberculosis culture was pelleted, resuspended in $1 \mathrm{ml}$ buffer $\mathrm{Z}$ $[0 \cdot 1 \mathrm{M}$ sodium phosphate $(\mathrm{pH} 7 \cdot 0), 10 \mathrm{mM} \mathrm{KCl}, 1 \mathrm{mM}$ $\mathrm{MgSO}_{4}$ and $50 \mathrm{mM}$ mercaptoethanol], disrupted using a Fast Prep FP120 bead-beater $\left(40 \mathrm{~s}\right.$ at $6.0 \mathrm{~m} \mathrm{~s}^{-1}$, using Lysing Matrix B) and centrifuged at 13000 r.p.m. to obtain the soluble cell extract. $\beta$-Galactosidase measurements were performed on the soluble cell extract, as described by Miller (1972); results are expressed in Miller units $\left[A_{420} \times 1000 /\right.$ reaction time $\left.(\min ) \times A_{550}\right]$.

For determination of the $\beta$-galactosidase activity in an infected macrophage cell line, the murine macrophage-like cell line J774 was cultivated in RPMI medium 1640 with $25 \mathrm{mM}$ HEPES buffer and L-glutamine supplemented with $10 \%$ fetal calf serum in $5 \% \mathrm{CO}_{2}$ at $37{ }^{\circ} \mathrm{C}$ in T25 flat-bottomed cellculture flasks. The cell line was incubated for $18-24 \mathrm{~h}$ until a density of $5 \times 10^{6}$ cells per flask was reached. Recombinant $M$. tuberculosis $\mathrm{H} 37 \mathrm{Rv}$ strains were grown in Middlebrook $7 \mathrm{H} 10$ medium containing $20 \mu \mathrm{g}$ kanamycin $\mathrm{ml}^{-1}$. The cultures were then harvested, resuspended in RPMI medium, vortexed, sonicated for $1 \mathrm{~min}$ in an ultrasonic cleaner and allowed to settle. The upper part of each of the bacterial suspensions (supposedly free of clumps of bacteria) was used to infect the J774 cell line. The $\mathrm{OD}_{650}$ value for the upper portion of the suspension was taken, and it was assumed that an $\mathrm{OD}_{650}$ value of $0 \cdot 1$ was equal to $10^{7}$ c.f.u. $\mathrm{ml}^{-1}$ (data not shown). This suspension was then used to replace the medium that the J774 cells were in, and infection of the J774 cells was performed at an m.o.i. of 100 . Infected cells were incubated for $3 \mathrm{~h}$, then washed five times with fresh RPMI medium. At 0, 1, 4 and 6 days post-infection, the J774 cells were scraped and lysed with $1 \mathrm{ml}$ of $1 \%$ Triton X-100 for $15 \mathrm{~min}$. The resulting suspension was centrifuged to obtain the mycobacterial pellet, and $\beta$-galactosidase activity was determined for the mycobacterial cells, as described above. Activity was related to the number of bacteria as determined by plating onto Middlebrook 7H11 agar supplemented with kanamycin and OADC. As a control, the $\beta$-galactosidase activity of the bacterial strains that were used for macrophage infection but grown in vitro was determined.

Gel-shift assay. A $100 \mathrm{bp}$ and a $206 \mathrm{bp}$ fragment from upstream of the start codon of $R v 1964$ (from mce3; see 'Construction of lacZ reporter fusions') and a $139 \mathrm{bp}$ fragment from upstream of $R v 0586$ of the mce 2 promoter region (obtained using primers P2up and P2low; Table 1) were used as probes in this assay. Fragments were labelled with $\left[\gamma^{32} \mathrm{P}\right]$ ATP by using the polynucleotide kinase enzyme. Nonincorporated nucleotides were eliminated from the mixture containing the labelled probes by using Wizard PCR Prep Columns (Promega). Labelled probes were incubated with the soluble cell extract from recombinant E. coli BL21 overexpressing Rv1963 or from E. coli BL21(pRSET) (negative control) in binding buffer [ $4 \%$ glycerol (v/v), $1 \mathrm{mM} \mathrm{MgCl}$, $0.5 \mathrm{mM}$ EDTA, $0.5 \mathrm{mM}$ DTT, $50 \mathrm{mM} \mathrm{NaCl}, 10 \mathrm{mM}$ Tris/ $\mathrm{HCl}(\mathrm{pH} 7 \cdot 5), 0.05 \mathrm{mg}^{2}$ salmon sperm DNA ml${ }^{-1}$ ] for $20 \mathrm{~min}$ at room temperature. The samples were separated by PAGE $[4 \%$ acrylamide gel containing $1 \times \mathrm{TBE}(0.05 \mathrm{M}$ Tris base, $0.05 \mathrm{M}$ boric acid, $1 \mathrm{mM}$ EDTA-Na $\left.2.2 \mathrm{H}_{2} \mathrm{O}\right), 0 \cdot 1 \%$ bisacrylamide and $2.5 \%$ glycerol] for $3 \mathrm{~h}$ at $100 \mathrm{~V}$, after a 30 min pre-run in a $0.5 \times$ TBE buffer tank. The gels were then dried and exposed to X-ray film.

\section{RESULTS}

\section{Characterization of a putative regulatory gene for the mce3 operon}

The $R v 1963$ gene is located upstream of the mce 3 operon (Fig. 1) and encodes a hypothetical protein of $44 \cdot 3 \mathrm{kDa}(407 \mathrm{aa})$. This ORF is homologous to the TetR family of regulators from several bacteria. The best 


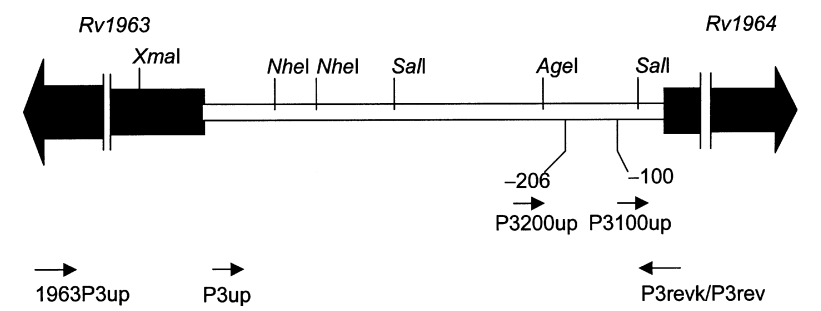

Fig. 1. Schematic representation of the Rv1963-Rv1964 intergenic region. Thick, solid lines represent the genes; the arrows indicate the direction of transcription. The open box represents the promoter-containing region. The primers used in amplifications, and their direction of action, are shown below the schematic. The -100 and -206 positions upstream of the Rv1964 start codon (ATG) are shown. Rv1964 is the first ORF of the mce3 operon. The restriction sites used for subcloning of the promoter region are also shown.
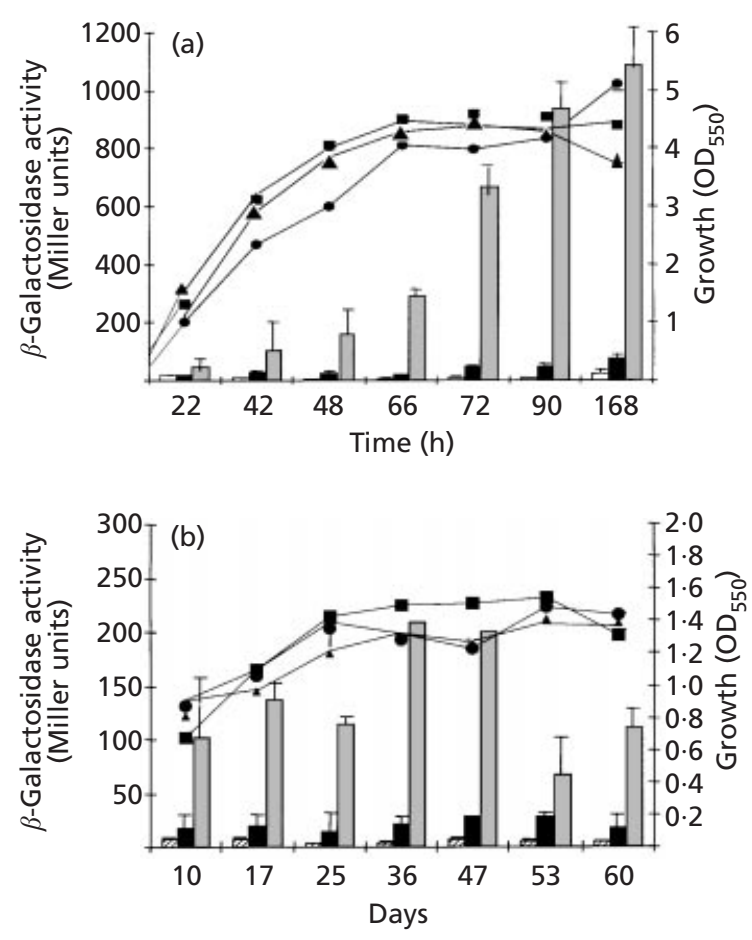

Fig. 2. Effect of Rv1963 on mce 3 promoter activity. Comparison of mce3 promoter activity during the growth of recombinant (a) $M$. smegmatis and (b) $M$. tuberculosis transformed with pJEM15 (vector alone as control), pP3 (construct without Rv1963) or p1963-P3 (construct with Rv1963). In both (a) and (b) the bars represent $\beta$-galactosidase activity; solid bars represent p1963-P3 and grey bars represent pP3. pJEM15 is represented by open bars in (a) and by hatched bars in (b). Growth curves for the recombinant strains are also shown in (a) and (b); $\boldsymbol{\Delta}$, strain transformed with pJEM15; $\mathbf{\square}$, strain transformed with p1963-P3; , strain transformed with pP3.

BLAST hits in GenBank were with putative regulatory proteins from Streptomyces coelicolor (accession no. AL163641; $42 \%$ similarity, E-value 6e-24) and $M$. tuberculosis (accession no. AE007094; $43 \%$ similarity, E-value 1e-08). These data suggest that the Rv1963encoded protein could regulate mce 3 transcription. Sequence analysis of the Rv1963 gene by PFAM showed two tet $R$-family signatures, one located at amino acids 19-65 and one, with a lower matching, located at amino acids 223-269. A helix-turn-helix motif was identified at amino acids $36-57$.

\section{The Rv1963 protein downregulates mce3 transcription}

To study the role of the putative regulatory gene $R v 1963$ in mce3 transcription, mycobacteria harbouring gene fusions between the mce3 promoter region and the Escherichia coli lacZ gene, either containing or not containing the Rv1963 gene, were used. M. smegmatis $\mathrm{mc}^{2} 155$ was transformed with these constructs and the $\beta$-galactosidase activity of the $M$. smegmatis transformants was measured throughout the growth of the cultures. $\beta$-Galactosidase activity was much higher in $M$. smegmatis $\mathrm{mc}^{2} 155(\mathrm{pP} 3)$ (minus $R v 1963$ ) than in $M$. smegmatis mc ${ }^{2} 155$ (p1963-P3) (plus Rv1963) (Fig. 2a). Significantly, a similar difference in activity was observed in M. tuberculosis $\mathrm{H} 37 \mathrm{Rv}$ transformed with the same constructs (Fig. 2b). These results indicate that the $R v 1963$-encoded protein negatively regulates the transcription of the mce 3 operon. Consequently, we propose to redesign $R v 1963$ as Mce3R. $\beta$-Galactosidase activity also greatly increased during the stationary phase of growth for M. smegmatis mc $^{2} 155$ (p3) (Fig. 2a). A similar increase in $\beta$-galactosidase activity was also observed for M. smegmatis $\mathrm{mc}^{2} 155(\mathrm{p} 1963-\mathrm{P} 3)$, although this activity was still at a lower level than seen for $M$. smegmatis $\mathrm{mc}^{2} 155(\mathrm{p} 3)$. The difference between the $\beta$-galactosidase activities of $M$. smegmatis $\mathrm{mc}^{2} 155(\mathrm{p} 3)$ and M. smegmatis $\mathrm{mc}^{2} 155(\mathrm{p} 1963-\mathrm{P} 3)$ remained approximately the same (17-fold) along the growth curves of the two strains. In the M. tuberculosis transformants, an increase in mce 3 expression was also observed during the stationary phase, but was followed by a decline during the later periods of this growth phase (Fig. 2b).

\section{Mapping of the mce3 promoter}

To map the mce 3 promoter, different segments of the $m c e 3 \mathrm{R}-\mathrm{R} v 1964$ intergenic region were assayed for their promoter activity (Fig. 3). A strain harbouring $\mathrm{pP} 3 \Delta \mathrm{X} m a /$ Age expressed high $\beta$-galactosidase activity (1100 Miller units). This result could be explained by the elimination of the mce3R repressor and suggests that the mce3 promoter is located between the AgeI site and the Rv1964 start codon. Deletion of a SalI-SalI fragment $(\Delta S a l)$ from the intergenic region abolished the expression of $m c e 3$, even in a strain lacking the repressor gene, suggesting that the promoter is located between the SalI sites or that it spans one of the SalI sites. Finally, strains harbouring plasmids with a NheI deletion $(\Delta \mathrm{NheI})$ showed no alteration in their $\beta$-galactosidase activities, demonstrating that the NheI-NheI segment 


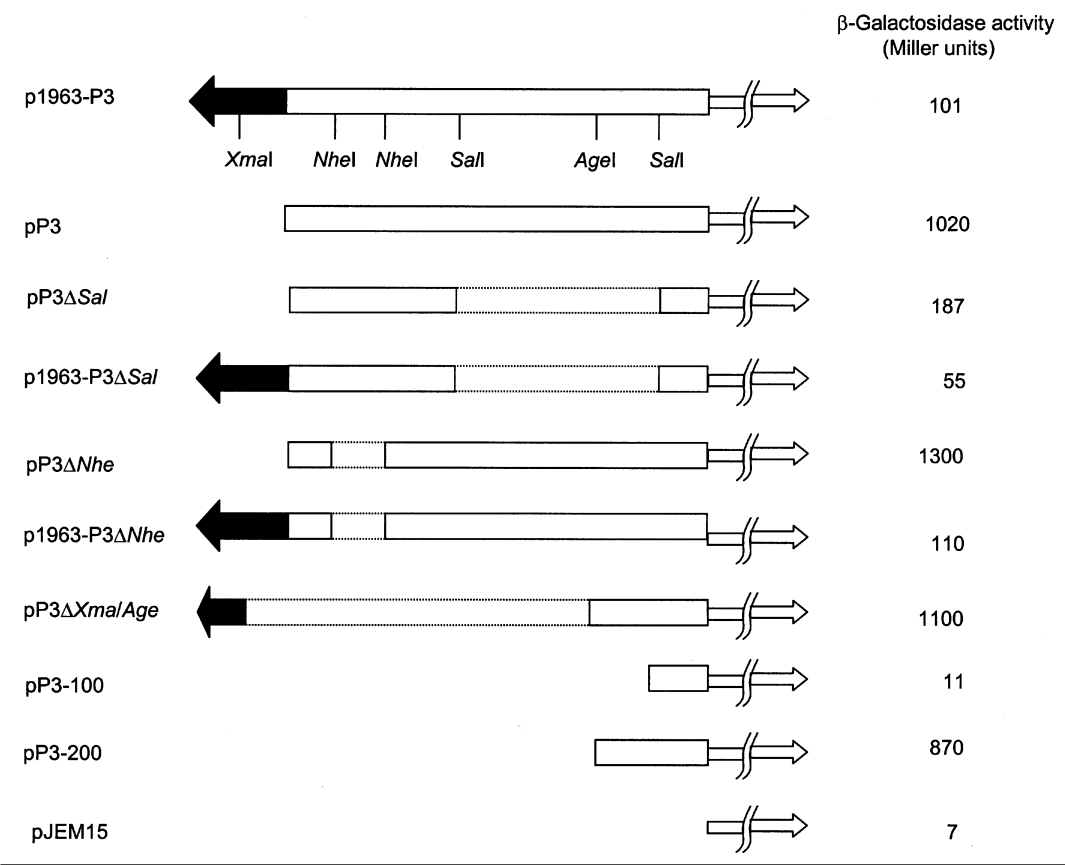

Fig. 3. Promoter activity of different segments of the Rv1963-Rv1964 intergenic region. Restriction sites used for deletion of segments are marked on the intact construct (p1963-P3). Deletions are marked by dotted lines; lacZ is represented by an open arrow; $R v 1963$ is represented by a solid arrow.

does not contain the mce 3 promoter nor the repressorbinding region. To further localize the $m c e 3$ promoter of M. tuberculosis, 206 and $100 \mathrm{bp}$ fragments from upstream of the start codon (ATG) of Rv1964 were evaluated for their promoter activity. To do this, these fragments were cloned into pJEM15 (generating pP3200 and pP3-100, respectively) and tested in M. smegmatis $\mathrm{mc}^{2} 155$. $\beta$-Galactosidase activity was 80 -fold higher in M. smegmatis $\mathrm{mc}^{2} 155$ (pP3-200) than in M. smegmatis $\mathrm{mc}^{2} 155$ (pP3-100), indicating that a functional mce 3 promoter is located between 100 and $206 \mathrm{bp}$ upstream of the $R v 1964$ start codon.

Primer-extension experiments (Fig. 4a) indicated that the transcription start point (TSP) of the mce 3 promoter was a C base 143 nt upstream of the Rv1964 start codon. A neural-network on-line program that searches for putative prokaryotic promoters located a probable promoter extending from -170 to -230 upstream of the ATG start codon corresponding to the first mce3 ORF (Rv1964). DNA STRIDER software identified putative -35 and -10 sequences in the proposed mce 3 promoter region (Fig. 4b), a probable -35 sequence, TAGCAA (extending from -204 to -198 ), with $4 / 6$ matches with the -35 consensus sequences of the $h s p 60$ promoter of BGC (TTGCAC) $(25 ; 27)$, and a probable -10 sequence, TATATG (extending from -182 to -178$)$, revealing $6 / 6$ matches with the typical E. coli -10 consensus sequence. The localization of these putative promoter hexamers coincides with the putative promoter found by the neural network. However, the -10 element is located at $-32 \mathrm{bp}$ of the TSP. One less consensual sequence, TATTTA, is localized $12 \mathrm{bp}$ upstream of the proposed TSP. A putative RBS was found by visual analysis of the downstream region of the proposed TSP (Fig. 4b).

\section{Expression of the mce3 operon in the cultured $\mathrm{J774}$ cell line}

To determine whether expression of the mce 3 operon was intracellularly induced, M. tuberculosis $\mathrm{H} 37 \mathrm{Rv}$ transformed with p1963-P3, pP3 or pJEM15 was used to infect the J774 macrophage-like cell line. The bacterial cells used for infection came from cultures at an $\mathrm{OD}_{650}$ value of $1 \cdot 2$ for M. tuberculosis H37Rv(pJEM15), 1.4 for M. tuberculosis $\mathrm{H} 37 \mathrm{Rv}(\mathrm{pP} 3)$ and 1.7 for M. tuberculosis $\mathrm{H} 37 \mathrm{Rv}(\mathrm{p} 1963-\mathrm{P} 3)$. At 0, 1, 4 and 6 days post-infection, cell lysates of the three transformants were prepared and their $\beta$-galactosidase activities were measured. The highest $\beta$-galactosidase activity was observed during the late stages of infection (4 and 6 days post-infection) in M. tuberculosis $\mathrm{H} 37 \mathrm{Rv}(\mathrm{pP} 3)$ and $M$. tuberculosis $\mathrm{H} 37 \mathrm{Rv}(\mathrm{p} 1963-\mathrm{P} 3)$. Induction of the mce3 operon in the infected J774 cell line was suggested by the comparison of $\beta$-galactosidase activity in vitro (bacteria used for infection) to that at 6 days post-infection. However, the M. tuberculosis $\mathrm{H} 37 \mathrm{Rv}(\mathrm{pP} 3)$ to M. tuberculosis $\mathrm{H} 37 \mathrm{Rv}(\mathrm{p} 1963-\mathrm{P} 3)$ ratio of $\beta$-galactosidase activity was similar in bacteria growing intracellularly and in those growing in vitro (around $8: 1$, Table 2), indicating that intracellular growth does not induce removal of repression in the experimental conditions used here.

\section{Binding of the Mce3R protein to the mce3 promoter region}

The Mce3R protein was examined for its ability to bind to the $m c e 3$ promoter region by performing a gel-shift assay. mce3R was cloned into the expression vector pRSET-A; high expression recombinant mce3R was then induced in E. coli BL21(pRSET1963) by the addition of IPTG to the growth medium (Fig. 5). Since 
(a)

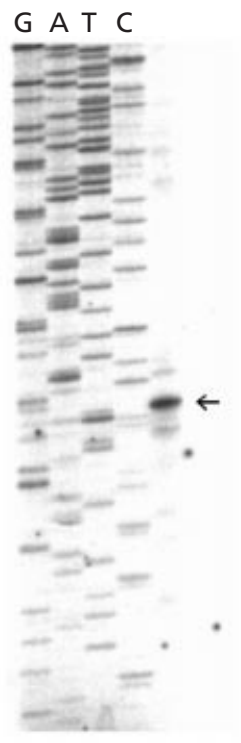

(b)

TACTAGCAAGATACATCATAGCCAATATATGCCAGTTTGCA TTGCTATTTACCGATCAGTTGTECAAGCAATCGCGTATTGG CTATGGACATCAGCGGTTCTGCCGCGTACGCTCACCAATG TCACCGATCGTCGACCTGTCCGGGGGGCCAGCGTGCGCC ACCTCACCCAACGGCCCAGCATCGAATCCAGCTGGTGCGC CGCGCC

Fig. 4. (a) TSP as determined by primer extension. The TSP is indicated by an arrow; sequencing products generated by using the Low861 primer are shown alongside. (b) Predicted promoter region of the mce 3 operon. The -10 (TATATG) and -35 (TAGCAA) regions are highlighted; an alternative -10 element (TATTTA) is also highlighted. A double-underlined C shows the TSP, as determined by primer extension. Letters in italics indicate putative ribosome-binding sites.

the formation of inclusion bodies by the bacterium prevented the purification of histidine-tagged Mce3R on nickel/agarose columns, we decided to work with the soluble fraction of the cell extract of E. coli BL21(pRSET1963), which contained Mce3R (Fig. 5). Three different probes were tested in gel-shift assays on

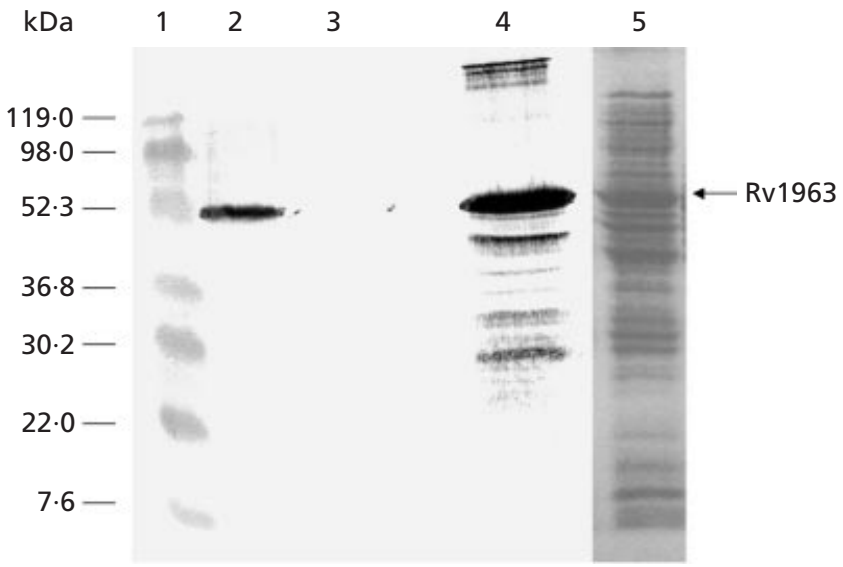

Fig. 5. Overexpression of Mce3R in E. coli BL21. Expression was induced by the addition of IPTG to the growth medium; Western blotting was done using an anti-His mAb. Lanes: 1, molecular mass markers; 2, soluble fraction of cell extract of $E$. coli BL21(pRSET1963); 3, whole-cell extract of E. coli BL21(pRSET-A); 4, insoluble cell extract of $E$. coli BL21(pRSET1963); 5, Coomassie-blue-stained cell extract of E. coli BL21(pRSET1963).

the cell extract of E. coli BL21(pRSET1963); these were 100 and $206 \mathrm{bp}$ fragments upstream of the start codon (ATG) of Rv1964 and a 139 bp fragment from the mce 2 promoter region. The $206 \mathrm{bp}$ fragment showed Mce3R binding to the mce 3 promoter region in a dosedependent manner (Fig. 6), whereas no binding was observed with the $100 \mathrm{bp}$ fragment. A cell extract from E. coli BL21 transformed with vector alone produced no retardation on the $206 \mathrm{bp}$ fragment. Interestingly, Mce3R bound to the $139 \mathrm{bp}$ mce 2 fragment, suggesting a regulatory action of Mce3R on the mce 2 promoter; however, the strength of this binding was lower than seen for Mce3R and the mce3 promoter.

\section{DISCUSSION}

Currently, the physiological function of Mce proteins is not known, although a protein promoting mammalian cell entry, Mcep (Arruda et al., 1993), is encoded by the mce 1 operon of M. tuberculosis. Mce proteins seem to be exported by the bacterium, as suggested by their

Table 2. Effect of Rv1963 expression on mce3 promoter activity in recombinant strains used to infect J774 cell line

\begin{tabular}{|lcrrr|}
\hline $\begin{array}{l}\text { J774 Macrophage-like cell line } \\
\text { infected with }\end{array}$ & $\begin{array}{c}\text { In vitro } \boldsymbol{\beta} \text {-galactosidase } \\
\text { activity (Miller units)* }\end{array}$ & \multicolumn{2}{c|}{$\boldsymbol{\beta}$-Galactosidase activity (Miller units) at } \\
\cline { 3 - 5 } & & $\mathbf{0}$ d.p.i. $\dagger$ & 1 d.p.i. & 4 d.p.i. \\
\hline M. tuberculosis H37Rv(pJEM15) & 2 & 22 & 20 & 185 \\
M. tuberculosis H37Rv(p1963-P3) & 21 & 49 & 55 & 454 \\
M. tuberculosis H37Rv(pP3) & 140 & 541 & 588 & 4684 \\
\hline
\end{tabular}

*Activity of bacterial cultures used as inoculum.

†d.p.i., Days post-infection. 


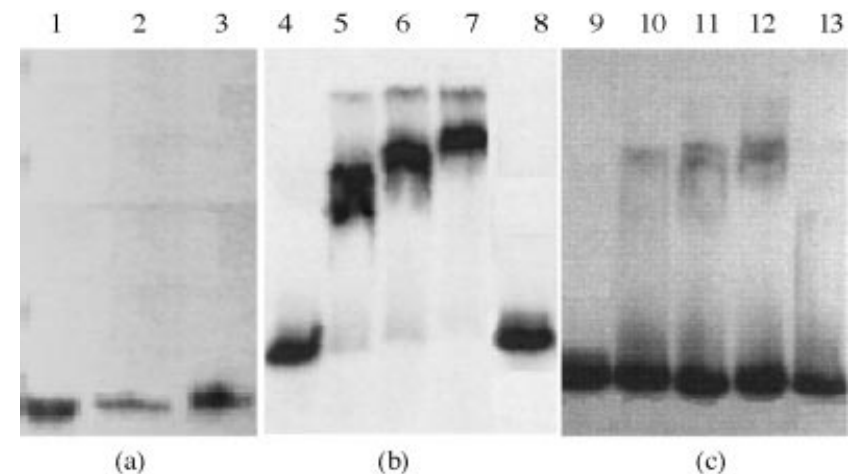

Fig. 6. DNA binding activity of Mce3R. Gel-shift analysis of different mce3 and mce2 promoter-containing regions. In (a), a $100 \mathrm{bp}$ fragment amplified from the mce 3 promoter region was used as the probe. Lanes: 1, probe incubated with PBS; 2 , probe incubated with $16 \mu \mathrm{g}$ of soluble cell extract from $E$. coli BL21(pRSET1963); 3, probe incubated with $32 \mu \mathrm{g}$ of soluble cell extract from E. coli BL21(pRSET1963). In (b), a 206 bp fragment amplified from the mce3 promoter region was used as the probe. Lanes: 4 , probe incubated with PBS; 5 , probe incubated with $27 \mu \mathrm{g}$ of soluble cell extract from E. coli BL21(pRSET1963); 6 , probe incubated with $54 \mu \mathrm{g}$ of soluble cell extract from E. coli BL21(pRSET1963); 7, probe incubated with $108 \mu \mathrm{g}$ of soluble cell extract from $E$. coli BL21(pRSET1963); 8, probe incubated with $30 \mu \mathrm{g}$ of soluble cell extract from $E$. coli BL21(pRSET-A). In (c), a $139 \mathrm{bp}$ fragment amplified from the mce2 promoter region was used. Lanes: 9, probe incubated with PBS; 10 , probe incubated with $27 \mu \mathrm{g}$ of soluble extract from E. coli BL21(pRSET1963); 11, probe incubated with $54 \mu \mathrm{g}$ of soluble extract from $E$. coli BL21(PRSET1963); 12, probe incubated with $108 \mu \mathrm{g}$ of soluble extract from $E$. coli BL21(pRSET1963); 13, probe incubated with $30 \mu \mathrm{g}$ of soluble cell extract from E. coli BL21(pRSET-A). Details for the probes used can be found in Methods.

predicted topology and by subcellular fractionation experiments (data not shown). The membrane localization of Mce proteins predicts a function for them in transmembrane transport, cell-wall synthesis or other functions associated with the bacterium-environment relationship. Genes encoding proteins homologous to those encoded by the mce operons are also present in other mycobacterial species, such as M. avium (Parker et al., 1995), M. smegmatis (http://www.tigr.org/tdb/ $\mathrm{mdb} / \mathrm{mdbinprogress.html)}$ and $M$. leprae (Cole et al., 2001). However, mce3 is absent from M. bovis and $M$. microti. The biological consequence of the absence of $m c e 3$ in these species is unclear, but it is important to note that although the mce 3 operon is deleted in $M$. bovis, $R v 1963$ is conserved within this species. In place of the mce 3 operon ORFs, the M. bovis genome has a chimeral ORF between Rv1964 and Rv1977. M. smegmatis also contains four operons with a structure similar to the mce operons of M. tuberculosis (data not shown). Surprisingly, in the M. smegmatis genome the gene most similar to $R v 1963$ is not upstream of the mce3-like operon, but is instead elsewhere in the genome. Also, upstream of the mce3-like operon there is another tetRlike regulator with a lesser homology to $R v 1963$ (data not shown).
Even though the expression of Mce proteins has been demonstrated both in vitro (Harboe et al., 1999) and in vivo (Ahmad et al., 1999), nothing is known about the regulation of production of Mce proteins. The observation of a regulatory-type gene in the vicinity of the mce 3 operon prompted us to determine whether this putative regulator controls mce expression. The $0.9 \mathrm{kbp}$ intergenic region between $R v 1963$ and $R v 1964$ should be the location of the mce 3 promoter and the target of regulatory proteins. Progressive deletions and cloning of this region helped us to map the promoter region in a fragment extending from the $R v 1964$ start codon to $206 \mathrm{bp}$ upstream of it. A neural-network search for putative prokaryotic promoters located a probable promoter extending from -170 to -230 upstream of the ATG start of the first mce3 ORF. As deduced from gel-shift assays, it was also observed that Mce3R binds to this region.

Using all of the published putative mycobacterial sequences, Mulder et al. (1997) calculated the mycobacterial promoter to consist of a -35 consensus sequence, TTGACG/A, and a -10 consensus sequence, TATA/ GA/CT. Putative -10 (TATATG) and -35 (TAGCAA) sequences were identified in the predicted promoter region of the mce3 operon. The proposed -10 hexamer is identical to the corresponding sequence in E. coli and conserves the four first positions of the Mulder et al. (1997) consensus sequence. The putative -35 sequence conserves three positions of the Mulder $e t$ al. (1997) consensus sequence and is identical to other individual mycobacterial promoters. However, the proposed -10 sequence is far ( $32 \mathrm{bp}$ ) from the TSP identified by primer-extension experiments. Possible explanations for this large separation could be (i) an erroneous TSP was mapped because the $5^{\prime}$ end of the transcript was processed or degraded, or (ii) nonconserved -10 and -35 sequences are present in the mce 3 promoter region. As in many actinomycete promoters, mycobacterial promoters not carrying the canonical -35 and -10 sequences have been reported. Counting upstream from the proposed start site of the mce 3 promoter region there is another, less consensual, sequence, TATTTA, at a distance of $-12 \mathrm{bp}$.

In general, the TetR family of bacterial regulators are repressors; many of these proteins regulate genes that encode proteins involved in membrane processes such as osmoregulation (Rkenes et al., 1996), permeability (Ma et al., 1996; Lucas et al., 1997; Namwat et al., 2001) and resistance to antibiotics or quaternary ammonium salts (Rouch et al., 1990; Grkovic et al., 1998), among other functions. The prototype TetR repressor is TetR from the Tn10 transposon of E. coli (Orth et al., 2000). There are approximately 40 tet $R$-family regulatory genes in M. tuberculosis (http://www.sanger.ac.uk/Projects/ M_tuberculosis). To the best of our knowledge, the $R v 1963$-encoded protein examined in this study (as Mce3R) is the first TetR-like regulatory protein whose function has been described in M. tuberculosis. As with other TetR regulators, a helix-turn-helix motif and a tet $R$-family signature sequence reside in the first third of 
the Rv1963 gene. Most TetR-like regulators have molecular masses ranging from 21 to $25 \mathrm{kDa}$; however, Mce3R (Rv1963) has a molecular mass $>25 \mathrm{kDa}$. We observed that other TetR-like proteins with molecular masses $>25 \mathrm{kDa}$ contain two consensus signatures, as does Mce3R (Rv1963). The last third of Mce3R (Rv1963) shows no homology to other proteins. The two TetRlike regulators most homologous to Mce3R (Rv1963), Rv2506 and Rv3557c, are in the vicinity of lipidmetabolism-related genes of the M. tuberculosis genome.

We could not find the inducer(s) of the mce 3 operon; different conditions of stress (ethanol, SDS or low carbon) did not abolish repression of expression (data not shown). No removal of repression was observed when the J774 macrophage-like cell line was infected with recombinant $M$. tuberculosis. The possibility exists that removal of repression could not be observed due to the fact that in recombinant mycobacteria carrying the reporter gene the repressor is harboured in cis in multicopy plasmids. However, an increase in mce3 expression by $M$. tuberculosis $\mathrm{H} 37 \mathrm{Rv}(\mathrm{pP} 3)$ and $M$. tuberculosis $\mathrm{H} 37 \mathrm{Rv}(\mathrm{p} 1963-\mathrm{P} 3)$ was observed in the later stages of J774 infection, suggesting that additional factors may affect mce 3 expression.

At present, it is not known whether the Rv1963-encoded protein regulates genes other than mce3, but gel-shift experiments indicated that Mce3R binds to the mce 2 promoter region, raising the possibility that mce 2 may also be negatively regulated by the $R v 1963$-encoded protein. However, the binding of the recombinant protein Mce3R to the mce 2 promoter seems to be weaker than binding of this protein to the mce3 promoter, suggesting that fine-tuning of regulation of the mce operons may occur. Interestingly, a moderately homologous region of about $100 \mathrm{bp}$ was found in the promoter-containing regions of $m c e 2$ and $m c e 3$ (data not shown).

The present study reveals interesting features of the control of expression of the mce operons of $M$. tuberculosis. It also poses a number of questions that need to be answered, such as (i) does the Rv1963encoded regulatory protein have the same effect on mce promoters other than $m c e 3$, and (ii) which extracellular signals are required for mce expression? At present, it is not known whether the mce1 and mce4 promoter regions are also the target of the $R v 1963$-encoded transacting regulatory factor, but the high homology between the mce operons supports the idea of a broader regulatory mechanism.

\section{ACKNOWLEDGEMENTS}

The present study was supported by grants from the Ministerio de Salud of Argentina (Beca Carrillo-Oñativia) and the International Foundation for Science. M.I.R., F.B. and A.C. are Fellows of the National Research Council (CONICET). A.A. and O.Z. are Fellows of the National Institute of Agricultural Research of Argentina (INTA). K.C. and M.Z. are recipients of a fellowship from CONICET, J.G. is the recipient of a fellowship from the Ministerio de Salud of
Argentina and M.P.S. is the recipient of a fellowship from FONCyT. We are grateful to Dr Eduardo Groisman and Dr Fernando Soncini for their critical reading of the manuscript.

\section{REFERENCES}

Ahmad, S., Akbar, P. K., Wiker, H. G., Harboe, M. \& Mustafa, A. S. (1999). Cloning, expression and immunological reactivity of two mammalian cell entry proteins encoded by the mce 1 operon of Mycobacterium tuberculosis. Scand J Immunol 50, 510-518.

Arruda, S., Bonfim, G., Knights, R., Huima-Byron, T. \& Riley, L. W. (1993). Cloning of an M. tuberculosis DNA fragment associated with entry and survival inside cells. Science 261, 1454-1457.

Bange, F. C., Collins, F. M. \& Jacobs, W. R., Jr (1999). Survival of mice infected with Mycobacterium smegmatis containing large DNA fragments from Mycobacterium tuberculosis. Tuber Lung Dis 79, 171-180.

Camacho, L. R., Ensergueix, D., Perez, E., Gicquel, B. \& Guilhot, C. (1999). Identification of a virulence gene cluster of Mycobacterium tuberculosis by signature-tagged transposon mutagenesis. Mol Microbiol 34, 257-267.

Cataldi, A., Romano, M. I. \& Bigi, F. (1994). A western blot characterization of Mycobacterium bovis antigens recognized by cattle sera. Res Microbiol 145, 689-698.

Chitale, S., Ehrt, S., Kawamura, I., Fujimura, T., Shimono, N., Anand, N., Lu, S., Cohen-Gould, L. \& Riley, L. W. (2001). Recombinant Mycobacterium tuberculosis protein associated with mammalian cell entry. Cell Microbiol 3, 247-254.

Cole, S. T., Brosch, R., Parkhill, J. \& 39 other authors (1998). Deciphering the biology of Mycobacterium tuberculosis from the complete genome sequence. Nature 393, 537-544.

Cole, S. T., Eiglmeier, K., Parkhill, J. \& 41 other authors (2001). Massive gene decay in the leprosy bacillus. Nature 409, 10071011.

Cox, J. S., Chen, B., McNeil, M. \& Jacobs, W. R., Jr (1999). Complex lipid determines tissue-specific replication of $\mathrm{Myco-}$ bacterium tuberculosis in mice. Nature 402, 79-83.

Fisanotti, J. C., Romano, M. I., Alito, A., Bigi, F. \& Cataldi, A. (1997). An $m p b$-64 flanking sequence specific for Mycobacterium bovis. Res Microbiol 148, 427-435.

Flesselles, B., Anand, N. N., Remani, J., Loosmore, S. M. \& Klein, M. H. (1999). Disruption of the mycobacterial cell entry gene of Mycobacterium bovis BCG results in a mutant that exhibits a reduced invasiveness for epithelial cells. FEMS Microbiol Lett 15, 237-242.

Gordon, S. V., Brosch, R., Billault, A., Garnier, T., Eiglmeier, K. \& Cole, S. T. (1999). Identification of variable regions in the genomes of tubercle bacilli using bacterial artificial chromosome arrays. Mol Microbiol 32, 643-655.

Grkovic, S., Brown, M. H., Roberts, N. J., Paulsen, I. T. \& Skurray, R. A. (1998). QacR is a repressor protein that regulates expression of the Staphylococcus aureus multidrug efflux pump QacA. J Biol Chem 273, 18665-18673.

Harboe, M., Christensen, A., Haile, Y., Ulvund, G., Ahmad, S., Mustafa, A. S. \& Wiker, H. G. (1999). Demonstration of expression of six proteins of the mammalian cell entry (mce1) operon of Mycobacterium tuberculosis by anti-peptide antibodies, enzymelinked immunosorbent assay and reverse transcription-polymerase chain reaction. Scand J Immunol 50, 519-527.

Lucas, C. E., Balthazar, J. T., Hagman, K. E. \& Shafer, W. M. (1997). The MtrR repressor binds the DNA sequence between the $m t r R$ and $m t r C$ genes of Neisseria gonorrhoeae. J Bacteriol 179, 4123-4128. 
Ma, D., Alberti, M., Lynch, C., Nikaido, H. \& Hearst, J. E. (1996). The local repressor AcrR plays a modulating role in the regulation of $\operatorname{acr} A B$ genes of Escherichia coli by global stress signals. Mol Microbiol 19, 101-112.

Mahairas, G. G., Sabo, P. J., Hickey, M. J., Singh, D. C. \& Stover, C. K. (1996). Molecular analysis of genetic differences between Mycobacterium bovis BCG and virulent M. bovis. J Bacteriol 178, 1274-1282.

Miller, J. H. (1972). Experiments in Molecular Genetics. Cold Spring Harbor, NY: Cold Spring Harbor Laboratory.

Mulder, M. A., Zappe, H. \& Steyn, L. M. (1997). Mycobacterial promoters. Tuber Lung Dis 78, 211-223.

Murray, C. J. L., Styblo, K. \& Rouillon, A. (1990). Tuberculosis in developing countries: burden, intervention and cost. Bull Int Union Tuberc Lung Dis 65, 6-24.

Namwat, W., Lee, C. K., Kinoshita, H., Yamada, Y. \& Nihira, T. (2001). Identification of the $\operatorname{var} R$ gene as a transcriptional regulator of virginiamycin $S$ resistance in Streptomyces virginiae. J Bacteriol 183, 2025-2031.

Orth, P., Schnappinger, D., Hillen, W., Saenger, W. \& Hinrichs, W. (2000). Structural basis of gene regulation by the tetracycline inducible Tet repressor-operator system. Nat Struct Biol 7, 215-219.

Parish, T. \& Stoker, N. G. (1998). Electroporation of mycobacteria. In Mycobacteria Protocols. Methods in Molecular Biology, vol. 101, pp. 120-144. Totowa, New Jersey: Humana Press.

Parker, S. L., Tsai, Y. L. \& Palmer, C. J. (1995). Comparison of PCR-generated fragments of the mce gene from Mycobacterium tuberculosis, M. avium, M. intracellulare, and M. scrofulaceum. Clin Diagn Lab Immunol 2, 770-775.

Rkenes, T. P., Lamark, T. \& Strom, A. R. (1996). DNA-binding properties of the BetI repressor protein of Escherichia coli: the inducer choline stimulates BetI-DNA complex formation. J Bacteriol 178, 1663-1670.

Rouch, D. A., Cram, D. S., DiBerardino, D., Littlejohn, T. G. \& Skurray, R. A. (1990). Efflux-mediated antiseptic resistance gene qacA from Staphylococcus aureus: common ancestry with tetracycline- and sugar-transport proteins. Mol Microbiol 4, 2051-2062.

Smith, H. (1984). The biochemical challenge of microbial pathogenicity. J Appl Bacteriol 47, 395-404.

Timm, J., Lim, E. M. \& Gicquel, B. (1994). Escherichia coli-mycobacteria shuttle vectors for operon and gene fusion to lac $Z$ : the pJEM series. J Bacteriol 176, 6749-6753.

van Soolingen, D., Hermans, P. W. M., de Haas, P. E. W., Soll, D. R. \& van Embden, J. D. A. (1991). Occurrence and stability of insertion sequences in Mycobacterium tuberculosis complex strains: evaluation of an insertion sequence-dependent DNA polymorphism as a tool in the epidemiology of tuberculosis. J Clin Microbiol 29, 2578-2586.

Zumarraga, M., Bigi, F., Alito, A., Romano, M. I. \& Cataldi, A. (1999). A $12.7 \mathrm{~kb}$ fragment of Mycobacterium tuberculosis genome is not present in Mycobacterium bovis. Microbiology $145,893-897$.

Received 22 April 2002; revised 9 May 2002; accepted 26 June 2002. 